Анна Суворова

\title{
ТАКТИКИ «МАРГИНАЛОВ»: К ПРОБЛЕМЕ МЕТОДОЛОГИИ АУТСАЙДЕРСКОГО ИСКУССТВА (ПОСТСОВЕТСКИЙ КЕЙС)
}

В статье обозначается проблема поиска релевантной методологии для анализа аутсайдерского искусства. Его изучение часто проводится при помощи концепта бессознательного и с позиций формального и семиотического анализа. Автор, напротив, изучает дискурсивность искусства и его связь с другими социальными полями (например, массовая культура и политика). В качестве релевантного подхода предлагается использование понятий дискурса, стратегий и тактик в интерпретации Мишеля де Серто. Де Серто называет стратегией расчет отношений сил, включающий утверждение собственного места, обладание которым дает преференции в управлении. Согласно этому подходу, различаются стратегии, которыми можно обозначить «большое искусство», поля политики, общества и науки. Стратегиям противостоят тактики аутсайдеров. Среди которых на основе анализа выделяются: тактики присваивания, захват «места другого», имитация стратегии, манипулирование и использование слабости. В качестве кейса, на основе которого происходит апробация указанного методологического подхода, выбираются истории художников-аутсайдеров, которые работали в период 1990-х начала 2010-х гг., но принадлежали разным поколениям. Опираясь на материалы интервью, произведения художников этого круга раскрываются через применение указанных тактик в искусстве аутсайдеров. Так, «браконьерство тактик» развивается в присваивании «метанарратива». Визуально это может проявляться через «захват нарратива», заимствование содержания из литературы, телепередач, увиденного в высоком искусстве - всего того, что было рождено полем «большой культуры». Подобная практика очень широко распространена в контексте маргинального и аутсайдерского искусства: пространства имитирующие ситуации музея, выставочного зала оказываются симулякром стратегии. Эти пространства - в терми-

Анна Суворова - кандидат искусствоведения, доцент, кафедра культурологии и социальногуманитарных технологии, Пермский государственный национальный исследовательский университет, Пермь, Россия. Электронная почта: suvorova_anna@mail.ru 
нологии де Серто «не-места» - формируют определенную силу тактик. Другими важными тактиками оказываются симуляция, притворство, переворачивание соотношения сил.

Ключевые слова: искусство аутсайдеров, методология, теория дискурса, стратегии, тактики

DOI: $10.17323 / 727-0634-2018-16-2-237-250$

В статье рассматривается применение теории, сформулированной Мишелем де Серто (2013), для анализа искусства художников-аутсайдеров 1990-х - начала 2010-х гг. Это новый подход в изучении феномена аутсайдерского искусства, поскольку зачастую он описывается при помощи психологизированных методологий о бессознательном или с позиций семиотического анализа. Выбор «говорящего субъекта» для анализа, то есть высказываний художников-аутсайдеров, обусловлен его позиционированием, позволяющим различать тактики и стратегии в терминах де Серто. В статье раскрывается типология тактик художников, появляющихся в ответ на более общие стратегии власти.

Отобранные для исследования художники отличаются своими жизненными историями и мотивами творчества. Будут проанализированы работы и интервью с Анной Аборкиной и Александром Лихановым и интервью с ними. Аборкина, чье личностное становление происходит в период позднего застоя и перестройки, осваивает практики «интеллигентного человека» с детства, она растет в окружении художников и литераторов. Художница родилась в 1957 г. в Перми в семье известного журналиста, получила высшее образование, работала филологом. Другой «говорящий субъект» - Лиханов - формируется как личность в период 2000-х гг. В его жизненную историю вплетены психиатрический опыт, заключение, прием психотропных веществ. Для него авторитетным дискурсом являются альтернативная музыка, религиозные течения и пермский Музей современного искусства. В силу специфики респондентов работа построена на основе интервью с Анной Аборкиной и Александром Лихановым. Сначала представлен краткий обзор формирования дискурса аутсайдерского искусства и уточнение его специфики, затем - обозначаются ключевые теоретические модели с опорой на работы Мишеля Фуко и Мишеля де Серто. На основе предлагаемой методологии строится анализ интервью с художникамиаутсайдерами. В статье анализируются тексты этих интервью, что позволяет выявить тактики (в терминах де Серто) художников-аутсайдеров.

\section{История аутсайдеров}

В середине XX в. происходит серьезное осмысление и изучение аутсайдерского искусства благодаря работам художника и теоретика Жана Дюбюффе. 
Он предложил термин ар брют для обозначения искусства, созданного за пределами официальной, лигитимизированной культуры (Dubuffet 1986). Понятие ар брют было применено Дебюффе по отношению к искусству людей, оказавшихся «за чертой», за пределами «правильных» социальных групп художественной школы, мира обычных людей. Интерес Дебюффе был обусловлен его коллекционерскими вкусами. После войны он начал искать необычные работы, созданные душевнобольными. Вскоре Дебюффе понял, что редкие индивидуальности из разных социальных слоев, не связанных с миром искусства, тоже могут быть художниками «непредвзятого» наивного взгляда на мир. Дебюффе собирал картины, рисунки и объекты, сделанные кондитерами, домохозяйками, мусорщиками и почтальонами. Он дал этому безымянному искусству определение и интеллектуальное обоснование. Ар брют - сырое искусство - было не обработано, не «приготовлено» культурой и не зависело напрямую от политики, образования или моды.

Непосредственность выражения, процесс чистого автоматизма, богатство художественных приемов, отсутствие влияний предшественников - все это было открытиями чистой визуальности и новацией в художественном высказывании. Дебюффе представлял культуру в качестве главного врага истинного творчества. В 1970-е гг. активизируется изучение такого наивного искусства, и искусствовед Роджер Кардинал предлагает термин искусство аутсайдеров - outsider art (Cardinal 1972), понятие, которое описывает более широкое поле, чем ар брют.

Зачастую предполагается, что искусство художников-аутсайдеров связано с бессознательным и/или является порождением психической болезни (Dubuffet 1986; Карпов 1926; Prinzhorn 1995). Одиозный классик психиатрии Чезаре Ломброзо в своем труде «Гениальность и помешательство» проводит взаимосвязи между характером творчества - стилем рисунков и текстов и видом психического расстройства (Ломброзо 1892). Эта работа оказала влияние на корпус ранних текстов об искусстве душевнобольных.

Десятилетиями позже Ханс Принцхорн описывает «нормальное» искусство как созданное по законам эпохи Возрождения (Prinzhorn 1995). Таким образом, поскольку Возрождение апеллирует к идее предметного искусства, то одним из признаков нормы оказывается фигуративность искусства. Принцхорн сближал «сложность» модернистских течений и шизофреническое формообразование, считая, что отказ от изображения реальных предметов означает передачу произведением только психического состояния. Это психологизированное понимание искусства аутсайдеров задает тон и его современному анализу. Дополнением стало лишь то, что границы искусства аутсайдеров становятся более обширными. Так, Джон Макгрегор включает в этот феномен не только работы непрофессионалов, но и творчество профессиональных художников, переживших психиатрический опыт (MacGregor 1989).

Анализируя произведения и суждения современных художников-аутсайдеров, мы видим, что в основе их искусства присутствуют политические, 
социальные и религиозные мотивы и темы (Гаврилов 2012; Суворова 2013, 2015). Возникновение внешнего основания для творчества в свете приведенных выше подходов к пониманию процесса его производства может показаться странным. Однако исследование с опорой на теорию Мишеля де Серто позволяет интерпретировать творчество аутсайдеров в связи с внешними социальными полями (политическими и социальными условиями, современными автору). Если подвергать дискурсивному анализу истории жизни художников-аутсайдеров, то можно выявить практики переозначивания различных элементов современной им культуры - от идеологического нарратива до популярных телепередач. Попытка выявить специфику этих «пересказов» приводит к поиску релевантной методологии в следующей части статьи.

\section{Методология анализа аутсайдерского искусства за пределами бессознательного}

Рассматривать искусство можно через развитие логики паноптизма Мишеля Фуко, т.е. ситуации тотального надзора за субъектом, осуществляемого художественными институтами. Власть функционирует и структурирует практики в поле искусства. По мысли Фуко, отдельный индивид - не только объект властного дискурса, но и ее эффект, производное (Фуко 1999). Художник - будь то профессиональный живописец или дизайнер, самодеятельный художник, занимающийся в кружке,- формируется через процессы нормализации и дисциплинарные практики (процессы копирования, срисовывания, пленэра или регулярного посещения занятий). А регулируем ли каким-либо образом художник-аутсайдер? Является ли он(а) эффектом власти?

«Внешние» связи художника-аутсайдера обусловлены его включенностью в те или иные сообщества или группы. Формально художник определяется как художник-аутсайдер, если он не связан с художественными сообществами, но это не значит, что он исключен из социального взаимодействия вовсе. Художник-аутсайдер как личность и гражданин функционирует в контексте существующей политики и повседневных отношений: например, включен в трудовой коллектив или кружок, коммуницирует с соседями, связан с семьей. Еще более влиятельным может оказываться социализирующий контекст медиа: информационного поля радио и телепередач, практик коммуникаций с другими институциями и представителями интеллектуальной культуры или искусства, как бы немногочисленны и специфичны не были эти контакты.

Согласно теории Фуко, знание является условием производства власти (Фуко 1999). В позиции официальной культуры наделение властью субъекта происходит тогда, когда он обладает некоторым легитимированным властью знанием: например, подтверждает свои знания дипломом. В неофициальных контекстах власть может конструировать другие типы знания. Так, в кругу 
советских интеллектуалов эпохи позднего застоя властью мог быть наделен обладающий знанием о британской рок-музыке. Более того, по Фуко, власть имеет горизонтальный характер - равные структурируют поведение равных, т.е. у всех есть рычаги влияния на других. Поэтому такая методология позволяет изучать не только макродискурсы, но и микрофизику власти, в том числе и прежде всего на примере взаимодействий художников-аутсайдеров с другими субъектами. Как происходит функционирование власти на микроуровне? Этот вопрос можно анализировать, взяв за основу индивидуальные истории жизни художников-аутсайдеров.

В поисках релевантного подхода для анализа индивидуальных историй художников-аутсайдеров можно обратиться к теории Мишеля де Серто. Как он пишет в «Изобретении повседневности», говорящий и пишущий всегда погружен в мир обыденного языка, таким образом он волен апроприировать язык и творчески истолковывать авторитетный дискурс (де Серто 2013). Процессы этой апроприации языка и множественность версий авторитетного дискурса, пусть самых странных и фантастических, мы видим в произведениях художников-аутсайдеров (Суворова 2013, 2015).

Де Серто обращается к книге «Надзирать и наказывать» Фуко, где подвергаются анализу не аппараты отправления власти (то есть локализуемые, репрессивные и правовые институты), а «диспозитивы» власти. Они реорганизуют функционирование власти, преобразуя стандартные формы ее отправления в дисциплину. Де Серто (2013) обозначает проблему теории Фуко: почему, несмотря на декларируемую тотальную систему «надзора» ею не исчерпывается все общество? Каким образом незаметные и повседневные процедуры (то, что делают люди) обходят механизмы подчинения? Какие именно практикуемые способы поведения оказываются сопротивлением социально-политическому порядку, т.е. как люди заново присваивают себе пространства?

По мысли де Серто, практики сопротивления - это процедуры и уловки большинства, «народная культура», которая выступает как способ производства приемов антисубъективации, практик, которые задействуют «народное» ratio, искусство комбинирования. Тем самым де Серто переосмысливает концепт маргинальности, которая в этой интерпретации перестает быть характеристикой малых групп. Маргиналы в этом случае являются большинством, маргинальность становится универсальной, но при этом не является гомогенной.

Применительно к анализу искусства, теория де Серто позволяет заключить, что культура постоянно формирует конфликты и попеременно легитимирует или смещает полномочия сильнейшего субъекта в свое поле. Ее развитие в контексте внутренних противоречий и конфликтного напряжения между субъектами формирует символические противовесы и соглашения, направленные на поддержание совместимости и компромисса отдельных элементов. Идеи зрелого авангарда начала XX в. и модернизма 
1950-х гг., в контексте которых формируется и усложняется поле «искусства душевнобольных» и искусства аутсайдеров, образуют некоторое репрессивное пространство. Оно враждебно по отношению к «неученому» зрителю, так как формальные и смысловые коды этих направлений изобразительного искусства требуют художественного и философского образования.

Мы предлагаем понимать аутсайдерское искусство как своего рода тактику, находящуюся в конфликтном отношении к доминирующим формам искусства. В этом случае под тактикой понимается идея Де Серто о сопротивлении более общим стратегиям власти. Стратегия, с точки зрения де Серто, это расчет отношений сил и манипулирование ими. Стратегия подразумевает существование места, которое может быть отграничено как свое собственное и которое можно определить как место собственной власти и воли. Тактики, напротив, являются противоположностью стратегий. Если стратегия - это победа «места» над «временем», тактика - это «не-место» (Де Серто 2013). Далее рассмотрим это разделение на материалах интервью с художниками-атсайдерами.

Применение теории Мишеля де Серто для анализа аутсайдерского искусства позволяет понять как тактики «маргиналов искусства» могут конкурировать со стратегиями «мета-нарратива» и в чем проявляются приемы «перетолковывания» доминирующего дискурса «маргиналами». Тактика в логике де Серто - действие, определяемое отсутствием собственного места. При этом место тактики - это место другого. Тактика - это извлечение выгоды из обстоятельств и потому зависят от них. В метафорическом смысле тактики «браконьерствуют», присваивая то, что «плохо лежит». Тактика это искусство слабого (Де Серто 2013). В следующей части именно так интерпретируются действия двух художников-аутсайдеров.

\section{Браконьерство тактик}

«Браконьерство тактик» раскрывается в присваивании «мета-нарратива». Визуально в художественных произведениях аутсайдеров это может быть проявлено через заимствование содержания из других источников: литературы, телевидения, высокого искусства. Иными словами, художественная практика аутсайдеров - это «захват нарратива», присвоение всего того, что рождено «большой культурой».

Авторы-аутсайдеры не обязательно прямо заявляют о таком «браконьерстве» в своих интервью. Скорее, наоборот, лукаво отвергают подобные ассоциации. Так, Аборкина, испытывая навязчивый интерес к мейнстриму говорит о его отсутствии: «Я никогда не любила Дягилева. Он никогда не был моим героем. Но почему-то я писала и писала Дягилева. И дягилевцев. ...И в конце кониов получилось картин шестьдесят». На уровне проговариваемых суждений мейнстрим мыслится аутсайдеру чуждым, но не при производстве художественных произведений: «Я не люблю 
Пушкина. Мой любимый поэт - Вяземский, Но Вяземский у меня один, a пушкиных у меня выше головы» (Аборкина 2014).

Иногда в творчестве аустайдеров мы сталкиваемся со случаями, в которых нарративы объединяют самые разные поля - от религиозного текста, тюремного фольклора, популярных телепередач, рок-музыки до современного искусства. Так, в случае с Сашей Лихановым подобная смесь различных заимствований, которая проявляется в его скульптурных объектах, рефреном присутствует и в его текстах:

Кому-то интересно взорвать ядерный реактор в один миг и по всей стране всемирная паутина интернета <..> БМВ: Бди, Молись, Веруй $<\ldots>$ Серёжа Зверев, тебя бог любит, чё ты творишь, блин $<\ldots .>$ Эдмунд Шклярский в натуре шаман (Козлов 2013).

Но иногда это «браконьерство» существует в виде смыслового «присваивания» персон большого искусства - через рассказы-воспоминания или мнимые воспоминания (часто иронические). Так, рассказывая о своем детстве, Аборкина описывает его как вращение между книжным издательством, Домом журналиста и квартирой, где семья проживала. Это было обусловлено местами работы отца и матери. А далее времяпрепровождение констатируется так:

Ведь книжное издательство дело серьезное. В общем, пришел ребенок надо же его как-то занять. Ведь ребенок может и залезть куда-нибудь, и высвиснуться из окна. И вот меня очень интересно и бойко стали привлекать к Маргарите Тарасовой. Это был единственный кабинет, где было весело. Это художник-оформитель (Аборкина 2014).

Маргарита Тарасова, на тот момент главный художник Пермского книжного издательства, дала девочке лист ватмана и кисть. А в интервью художница рассказывает, как Тарасова с ее мамой пошли в «комнату, где секретами делились», но маленькая Аня подслушала из разговор:

ну особо ничего нового я там не услышала. Но Маргарита сказала: «Нина, у тебя очень талантливая дочь и если она не хочет учиться в школе, то давай ее буду учить я» (Аборкина 2014).

Однако она тут же иронически отзывается о «девках в сарафанах» и «щуках с петрушкой в зубах» на тарасовских рисунках. Похожая история случилась и с другим маститым художником - Анатолием Тумбасовым, который тоже предлагал учить маленькую Аню, но «тут я вылезла. Сказала, что ваши эти кочегары меня совершенно не интересуют. И деревни развалившиеся». В историях об интересе со стороны мэтров «большого искусства» художница определяет себя как их полная противоположность, в терминах сопротивления темам и техникам художников из истеблишмента. 
Тем не менее иронизируя над авторитетом «большого искусства», аутсайдеры заимствуют его язык и идеи. Это «браконьерство» активно проявляется через использование композиционных схем, цветовой и тональной специфики изображения, нарратива. Но с изменением поля «большой культуры» трансформируется и специфика заимствований, новое также оказывается захвачено тактиками аутсайдеров. Так, например, в нарративе и формальном языке аутсайдеров объектами присваивания становятся учение Елены Блаватской, проповеди эзотерических гуру, хлынувших в страну на рубеже 1980-1990-х гг. (Валерий Щекалов); Александр Солженицын и его «Как нам обустроить Россию?» (Мансур Закиров); Марат Гельман, «русское бедное» и сатанизм (Александр Лиханов). Браконьерство тактик может показаться всеядным, они захватывают и присваивают культурные течения и религиозные феномены, историю и современность, персоналии и массовые визуальные клише.

Творческие и личные стратегии художников-аутсайдеров представляют примеры победы «слабого» над «сильным». Если у де Серто в качестве такой тактики присваивания оказывается чтение, которое по своим характеристикам является некоторым молчаливым производством, включающим скольжения взгляда по странице, «перепрыгивание» в пространстве книг, то в случае с художниками-аутсайдерами - практики перекраивания, копирования, мимикрии в определенные темы, формальные каноны и языки.

\section{Тактики аутсайдеров и «место другого»}

В понимании де Серто «стратегия» утверждает место, очерченное как собственное, и именно оно становится основой для управления отношениями с внешним пространством. В искусстве внешние границы очерчиваются институциями - учебными заведениями, музеями, творческими союзами. Художники-аутсайдеры преимущественно изъяты из этих «мест»: не включены в действующие союзы художников, не организовывают свои; в отличие от мастеров самодеятельного искусства аутсайдеры не обучаются в студиях (несмотря на эпизодически возникающий интерес к их деятельности). Однако в силу трансформации поля искусства они оказываются в этих специальных пространствах. Впрочем, в любом случае эскапизм не является сознательным для аустайдеров, это просто сложившееся положение вещей, которое, впрочем, может презентоваться осознанным: «Я человек не коллективный <...> Меня это пугает, мне это неинтересно» (Аборкина 2014).

Вместо принадлежности полю «большого искусства», аутсайдеры выбирают тактики, позволяющие фрагментарно проникать в его пространства: «Я позвонила в галерею и сказала, чтобы ко мне прислали искусствоведа, чтобы он оценил мои работы. Так вот, нагло. Там меня никто не знал, и я никого не знала» (Аборкина 2014). Тактика, не имея своего места, функционирует в пространстве другого. Жажда легитимации и отсутствие власти над официальным пространством искусства, формируют фрагментарные 
попытки его захвата. В случае неудачи происходит адаптация этих поползновений, разворачивание их в других полях, мимикрия в формы стратегий большого искусства:

...Послали Тамару Дмитриевну Шматенок. Тамара Дмитриевна вдруг засуетилась и говорит: «Анна, будем делать выставку. У вас есть зал?» $<$.. > Вот первая моя такая серьезная выставка была в десятом году в Доме журналиста $<\ldots>$ вторая выставка у нас была в Библиотеке духовного возрождения. А потом пошло: библиотеки, театры (Аборкина 2014).

Подобная практика распространена в контексте маргинального и аутсайдерского искусства: пространства, имитирующие ситуации музея, выставочного зала, будь то библиотека или собственный подъезд, оказываются альтернативой, симуляцией «места».

Поле современного искусства также осваивается аутсайдерами. Например, Лиханов, принося скульптуры в Музей современного искусства, объясненяет: «Мне было так сказано во сне. Сказано, что я должен отнести их все Гельману» (Козлов 2013). Но тактики, не обладая пространством полностью, проникают в него лишь фрагментарно; они не могут быть независимы от обстоятельств, как показано выше при обсуждении идей де Серто. Важно, однако, что эта фрагментарность оправдывается самим положением аутсайдера, не без доли лукавства:

А потом пошло: библиотеки, театры... А потом я устала от этого. <... А потом, когда мне последнюю выставку предложили - я сказала нет. Я вообще люблю говорить «нет». Это мое любимое слово (Аборкина 2014).

Альтернативные официальным галереям «не-места» демонстрируют силу тактики, когда художники-аутсайдеры ловят выгодный момент. При помощи тактик они манипулируют событиями, создавая благоприятные для себя ситуации. Будучи слабым, использующий тактики должен обращать в свою пользу чуждые ему силы:

У меня было несколько выставок в галерее. Такие детские выставки. Отбирали лучшие. В школе у меня были выставки. Я добралась до городской выставки. А республиканская - отец сказал нечего делать туда ездить. Еще голову снесут. Но я и не рвалась. Не тянуло, в общем (Аборкина 2014).

Это высказывание раскрывает следующую важную характеристику тактик аутсайдеров, которая отчасти обсуждалась выше: речь идет о симуляции и притворстве.

\section{Использование и потребление}

В качестве примера тактик использования и потребления де Серто приводит ребенка, разрисовывающего и пачкающего школьный учебник, 
несмотря на страх наказания. Так ребенок создает свое собственное пространство, в котором он существует в качестве автора. Другой кейс, рассматриваемый де Серто, это использование в своих интересах индейскими народностями законов, практик или репрезентаций, которые навязывались им силой испанскими колонизаторами. Таким образом, коренное население оставалось другим внутри системы, внося в нее искажения, но не выходя за ее пределы.

В этих примерах стратегии, формально обладая властью распространять свою власть, словно «попадают» в ловушки, которые созданы подпольными практиками. Иными словами, доминирующее положение стратегий, по мысли де Серто, является кажущимся и служит рамкой для вездесущих повседневных практик, использующих его в своих интересах. В тактиках слабых стратегия начинает работать на них. Именно в таком свете можно рассмотреть саморепрезентации художника-аутсайдера:

Пермский Пиросмани... Сначала меня это ярило, страшно ярило. Потом я успокоилась. Тем более, что я себя не считаю наивным художником. Я могу написать картину в наивном стиле. Могу. И мне это даже очень легко. Гораздо легче мне написать картину не в наивном стиле (Аборкина 2014).

Пиросмани, впрочем, не является достаточно авторитетным в повествовании, и художница добавляет в эту историю Академию художеств как более веский в ее глазах социализирующий институт. При этом она иронизирует в отношении признания со стороны института, чтобы утвердить свою позицию аутсайдера:

И вот ленинградская художница, которая окончила Академию художеств, и она тут оценивала мои картины, она сказала, что, не мне сказала, сказала, что отвяжитесь от нее со стилями, у нее нет стиля. Она сама стиль. Она уникальная. Она не ребенок, у нее никакого детского взгляда нет. Она трагический художник (пауза). Я была счастлива (пауза) $<\ldots>$ наконец-то меня поняли, наконец-то мне не надо доказывать, да не Пиросмани же я! (Аборкина 2014).

Де Серто также рассматривает способы использования языка для реализации тактик слабых. Язык обретает реальность только в акте речи, именно в нем происходит реализация лингвистической системы, открывается возможность для присвоения языка говорящим. При этом происходит учреждение настоящего за счет введения «Я» говорящего и организация текущей темпоральности (Де Серто 2013). В этой связи важно отметить, что в языке художников-аутсайдеров происходит заимствование и переработка не только «больших имен» или «громких» институтов, но и концептов и понятий. Они тоже начинают прямо или косвенно работать на художника:

Закончила я семьдесят седьмую школу английскую. Училась я хорошо, даже очень хорошо <...> а вот после были такие побоища. Отец кричал, чтобы я шла на журналистику. Я ему сказала, папа, одного журналиста 
на семью хватит. Ты знаешь, сколько мы с мамой терпим от твоей гениальности? А если еще второй гений появится? (Аборкина 2014).

Здесь Аборкина переосмысливает понятие «гений», иронически отказываясь называться так в собственном нарративе. Таким образом, захват и эксплуатация стратегий, в том числе переосмысление концепций языка, для художников-аутсайдеров является одной из распространенных тактик. Творчески перерабатывая язык, художники-аутсайдеры проводят аналогии между собой и художниками из истеблишмента, транслируют идеи мессианства (как Александр Лиханов) и иронически переосмысляют связи с «большим искусством».

\section{Заключение}

Проблема исследования различных феноменов искусства за пределами нормируемого, будь то искусство аутсайдеров, ар брют, маргинальное искусство и другие близкие им явления, нуждается в поисках релевантной методологии. Методы формального и семиотического анализа, часто применяемые к этому полю, не охватывают всей сложности этих явлений. Легитимация и развитие этих феноменов связаны с дискурсами культуры, науки, политики. Таким образом, артикуляции ар брюта, аутсайдерского и маргинального искусства требуют работы с дискурсивными методологиями, к которым может быть отнесена теория тактик.

В качестве общего смыслового подхода в анализе указанных феноменов выше была применена теория тактик, описанная Мишелем де Серто. Применение теории де Серто к материалу искусства аутсайдеров позволило выявить функционирование тактик этих художников. Художники-аутсайдеры используют тактики присваивания (браконьерства) стратегий, они заимствуют нарративы, языки и визуальные коды «большого искусства» и массовой культуры, захватывают «место другого», посредством репрезентации в новых пространствах или имитации стратегий.

В контексте культурной политики работа художественных институций и дальнейшее исследование искусства аутсайдеров логично укладывается в ситуацию постиндустриального общества. Понимание ценности и уникальности каждого индивида, осознание «многополярности» художественного процесса, переосмысление подхода к интерпретации и презентации искусства аутсайдеров могут стать основой для разработки культурной политики, направленной на работу с неинституализированным сообществом безвестных художников.

\section{Список источников}

Аборкина (2014) Интервью с Анной Аборкиной. Доступно по ссылке: https://www. youtube.com/watch?v=AelusLc9ItA (дата обращения: 30 января 2017). 
Гаврилов В. (2012) Аутсайдер арт и своеобразие визуальных документов «психиатрического опыта». Доступно по ссылке: http://www.medpsy.ru/mprj/archiv_ global/2012_2_13/nomer/nomer20.php (дата обращения: 30 марта 2017).

Де Серто М. (2013) Изобретение повседневности. 1. Искусство делать. СПб.: Издво Европейского университета в Санкт-Петербурге.

Карпов П. (1926) Творчество душевнобольных и его влияние на развитие науки, искусства и техник. Л.: Государственное издательство.

Козлов И. (2013) Христос предъявит всем. Доступно по ссылке: https://snob.ru/ profile/26721/print/58665 (дата обращения: 31 января 2017).

Ломброзо Ч. (1892) Гениальность и помемательство. СПб.: Изд. Ф. Павленкова.

Суворова А. (2013) Аутсайдерское искусство постсоветского периода в контексте кризиса идентификации. Искусство наивных художников в контексте отечественной и мировой художественной культуры: Материаль научной конференции. М.: Академика:51-58.

Суворова А. (2015) Проблемы методологии искусства аутсайдеров: кейс Мансура Закирова. А.С. Мигунов (ред.) Странныий художник. М.: МГУ: 178-184.

Фуко М. (1999) Надзирать и наказывать. Рождение тюрьмы. М.: AdMarginem.

Cardinal R. (1972) 'Cultural Conditioning'. Outsider Art. London: Studio Vista.

Dubuffet J. (1986) Asphyxiating Culture and other Writings. New York: Four Walls Eight Windows.

MacGregor J.M. (1989) The Discovery of the Art of the Insane. Princeton: Princeton University Press.

Prinzhorn H. (1995) Artistry of the Mentally Ill: A Contribution to the Psychology and Psychopathology of Configuration. Wien: Springer-Verlag. 
Anna Suvorova

\title{
THE TACTICS OF 'MARGINALS': THE ISSUE OF METHODOLOGY IN ANALYSING OUTSIDER ART IN THE CASE OF THE POST-SOVIET SPACE
}

\begin{abstract}
This article considers the problem of finding a relevant methodology for outsider art studies, which cannot be described with standard approaches usual in this field, such as the concepts of the unconscious and that of formal and semiotic analysis. Instead, the approach taken is to examine discursivity of outsider art and its significant relationship with external fields such as art, popular culture and politics. Thus, the concepts of discourse, strategies, and tactics are highly relevant, particularly in the theory of Michel de Certeau, who outlined the strategy of examining 'high art', as well as the fields of politics, society, or science. The article describes the most common tactics of outsiders: the tactics of assigning (poaching), the capture of 'the place of the other', and alerting or imitation strategies, as well as manipulation, and the usage of weakness. Based on interviews, the works of artists in this circle are considered in the light of these tactics in the art of outsiders. Thus, 'poaching tactics' are developed in the assigning of the official meta-narrative. Visually, this can be manifested through a 'capture narrative', borrowing the contents of literature, TV, 'high art' - all that is born from 'great culture'. This practice is widespread in the context of marginal and outsider art. Another important tactic comes in the form of simulation or sham, a turning in the balance of forces. The research is based on the stories of different generations of the outsider artists who worked from the 1990's to the early 2010s.
\end{abstract}

Key words: outsider art, methodology, discourse theory, strategy, tactics

DOI: 10.17323/727-0634-2018-16-2-237-250

\section{References}

Aborkina, A. (2014) Interv' ju s Annoj Aborkinoj [Interview with Anna Aborkina]. Available at: https://www.youtube.com/watch?v=AelusLc9ItA (accessed 30 January 2017).

Cardinal R. (1972) 'Cultural Conditioning'. Outsider Art. London: Studio Vista.

De Certeau M. (2013) Izobretenie povsednevnosti. 1. Iskusstvo delat' [The Invention of Everyday Life. 1. The Art of Making]. St. Petersburg: Izd-vo. Evropejskogo universiteta v Sankt-Peterburge.

Dubuffet J. (1986) Asphyxiating Culture and Other Writings. New York: Four Walls Eight Windows.

Anna Suvorova - Candidate of Art History, Associate Professor at the Cultural Studies and Social and Humanitarian Technologies Department, Perm State University, Perm, Russian Federation. Email: suvorova_anna@mail.ru 
Foucault M. (1999) Nadzirat' i nakazyvat'. Rozhdenie tjur'my [Discipline and Punishment: The Birth of the Prison]. Moscow: Ad Marginem.

Gavrilov V. (2012) Autsajder art i svoeobrazie vizual'nyh dokumentov 'psihiatricheskogo opyta' [Outsider Art and the Uniqueness of Visual Documents of 'Psychiatric Experience']. Available at: http://www.medpsy.ru/mprj/archiv_global/2012_2_13/nomer/nomer20.php (accessed 30 January 2017).

Karpov P. (1926) Tvorchestvo dushevnobol'nyh i ego vlijanie na razvitie nauki, iskusstva i tehnik [Creative Mentally Ill People and Their Influence on the Development of Science, Art and Technology]. Leningrad: Gosudarstvennoe izdatel'stvo.

Kozlov I. (2013) Hristos pred' javit vsem [Christ Indicts Everybody]. Available at: https:// snob.ru/profile/26721/print/58665 (accessed 31 January 2017).

Lombroso C. (1864) Genial'nost' ipomeshatel'stvo [Genius and Insanity]. St. Petersburg: F. Pavlenkov Press.

MacGregor J. M. (1989). The Discovery of the Art of the Insane. Princeton: Princeton University Press.

Prinzhorn H. (1995) Artistry of the Mentally Ill: A Contribution to the Psychology and Psychopathology of Configuration. Wien: Springer-Verlag.

Suvorova A. (2013) Autsajderskoe iskusstvo postsovetskogo perioda v kontekste krizisa identifikacii [Outsider Art of Post-soviet Period in the Context of a Crisis of Identification]. Iskusstvo naivnyh hudozhnikov v kontekste otechestvennoj i mirovoj hudozhestvennoj kul'tury: Materialy nauchnoj konferencii [The Art of Naive Artists in the Context of National and World Fine Art: Proceedings of an academic conference]. Moscow: Akademika: 51-58.

Suvorova A. (2015) Problemy metodologii iskusstva autsajderov: kejs Mansura Zakirova [The Problem of Methodology of Outsider Art: The Case of Mansur Zacirov]. A. S. Migunov (red.) Strannyj hudozhnik [A Weird Artist]. Moscow: MGU: 178-184. 